\title{
A Reconfigurable WiMAX Antenna for Directional and Broadside Application
}

\author{
M. Jusoh, ${ }^{1}$ M. F. Jamlos, ${ }^{1}$ M. R. Kamarudin, ${ }^{2}$ and T. Sabapathy ${ }^{1}$ \\ ${ }^{1}$ Advanced Communication Engineering Centre (ACE), School of Computer and Communication Engineering, \\ Universiti Malaysia Perlis (UniMAP), Kampus Pauh Putra, Arau, 02600 Perlis, Malaysia \\ ${ }^{2}$ Wireless Communication Centre (WCC), Faculty of Electrical Engineering, Universiti Teknologi Malaysia (UTM), \\ Skudai, 81310 Johor, Malaysia
}

Correspondence should be addressed to M. Jusoh; ame_tangol@yahoo.com

Received 28 February 2013; Accepted 25 April 2013

Academic Editor: Mohd Tarmizi Ali

Copyright (C) 2013 M. Jusoh et al. This is an open access article distributed under the Creative Commons Attribution License, which permits unrestricted use, distribution, and reproduction in any medium, provided the original work is properly cited.

\begin{abstract}
A novel reconfigurable compact patch array antenna for directional and broadside application is proposed. The presented antenna has successfully been able to function for directional beam at $320^{\circ}$ or $35^{\circ}$ and divisive broadside beam at $43^{\circ}$ and $330^{\circ}$. This is realized in the unique form of aperture coupled spiral feeding technique and positioning of the radiating elements at $0^{\circ}, 900^{\circ}$ and $180^{\circ}$. The switchable feature is effectively performed by the configuration of three PIN diodes. All PIN diodes are positioned at the specific location of the aperture coupled structure. It is discovered in simulation that the switches can be represented with a copper strip line or touchstone (TS) block. The proposed antenna design operates at $2.37 \mathrm{GHz}$ to $2.41 \mathrm{GHz}$ and has a maximum gain of $6.4 \mathrm{~dB}$ and efficiency of $85.97 \%$. Such antenna produces a broadside HPBW with a wider bandwidth covering from $-90^{\circ}$ to $90^{\circ}$ compared to the normal microstrip antenna which could only provide HPBW of $-50^{\circ}$ to $50^{\circ}$. Moreover, the proposed antenna has small physical dimension of $100 \mathrm{~mm}$ by $100 \mathrm{~mm}$. The simulation and measurement results have successfully exhibited the idea of the presented antenna performance. Therefore, the antenna is sufficiently competent in the smart WiMAX antenna application.
\end{abstract}

\section{Introduction}

In light of the rapid growth of wireless technology, the requirement of an antenna with a higher data rate, robust to interference, and minimum bit error rate (BER) is exceptionally crucial [1]. Therefore, a special antenna design with an enhancement of the antenna performance is the main challenge. A switched beam or adaptive array antenna could be the solution. Recently switched beam has gained a huge attention among the researchers and industrial players. Owing to this, it is important to design a switchable beam antenna with the ability to direct the main beam towards the desired signal while suppressing the antenna beam in the direction of the unwanted signal.

The fast-growing technology in microstrip antennas has led numerous researchers on the study of reconfigurable beam patch antenna [2-4]. Ali et al. [2] Proposed a reconfigurable planar antenna array (RPAA) by integrating with parasitic elements to achieve a beam steering capability.
The reconfigurable ability is realized using a PIN diode switch to steer the beam to the desired direction angles of $-3.0^{\circ}$, $0.0^{\circ}$, and $2.0^{\circ}$. Yusuf and Gong [3] achieved a beam steering direction angle of $-20^{\circ}$ to $+20^{\circ}$ with five different reactive loading values. In that work, a low-cost patch antenna, with center element excited by $50 \Omega$ inset current, has driven two neighboring elements via a mutual coupling effect. This patch antenna was fabricated and measured at a frequency of $3 \mathrm{GHz}$. Antenna in [4] successfully obtained two dedicated angles of $0^{\circ}$ and $270^{\circ}$ with activation of probe 1 and probe 2 , respectively. The hollow cylindrical dielectric pellet antenna with permittivity of six has been designed to operate at the frequency resonant of $9.53 \mathrm{GHz}$ and $11.1 \mathrm{GHz}$.

This paper demonstrates a novel antenna design with reconfigurable beam of directional and divisive broadside application. The proposed antenna has the capability to direct its radiation pattern to $320^{\circ}$ and $35^{\circ}$ at a particular predefined switches. Moreover, the divisive broadside can cater direction at $43^{\circ}$ and $330^{\circ}$. Therefore, the proposed antenna with 
World Interoperability for Microwave Access (WiMAX 2.3 GHz)

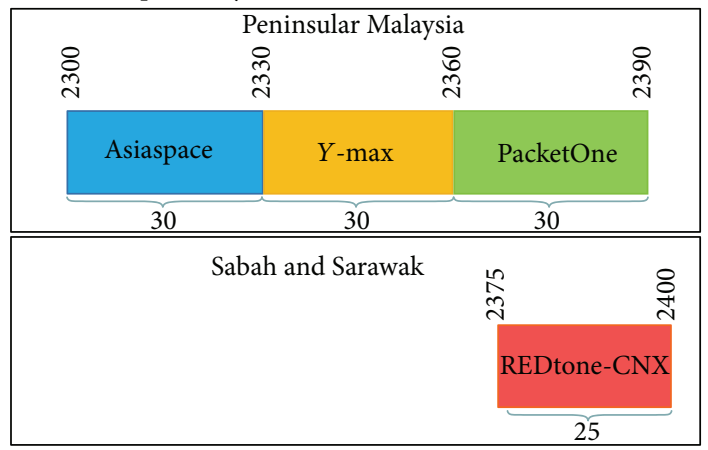

FIgURE 1: Malaysian Spectrum Allocation Chart of WiMAX $2.3 \mathrm{GHz}$ [5].

a wider HPBW which can be covered in $-90^{\circ}$ to $+90^{\circ}$ is better compared to the similar performance of antennas as discussed in $[6,7]$. Furthermore, each direction has successfully achieved a maximum beam direction of $3.35 \mathrm{dBi}, 3.21 \mathrm{dBi}$, and $2.80 \mathrm{dBi}$, respectively. To the best of our knowledge, none of reconfigurable beam antenna has achieved peak gain performance at all reconfigurable beam direction $[8,9]$.

The reconfigurable radiation pattern is achieved by the configuration of the radio frequency switches (R-RFS). Theoretically, the switchable antenna can be realized by using radio frequency (RF) switches such as PIN diodes, varactor diodes, MEMs, and GaAs FETs. The changes of these device states, "ON" and "OFF" at the specific position, would function as a frequency tuning $[10,11]$ or act as a impedance-matching devices $[12,13]$.

In terms of size, the proposed antenna with the dimensions of $100 \mathrm{~mm} \times 100 \mathrm{~mm}$ is smaller than the conventional microstrip antenna with the similar performance $[2,14-16]$. Another unique benefit of the proposed antenna lies in its design. It is discovered on the proposed antenna that the spiral feed line with various aperture slot dimensions and positions has significantly contributed to the successfulness of the directions and divisive beam performance. Moreover, the sequence radiating element placement of $90^{\circ}, 180^{\circ}$, and $270^{\circ}$ also leads to the achievement of reconfigurable beam capability. Besides that, the proposed aperture coupled technique has separated the radiating element and the feeding network that eventually contributed to the reduction of the spurious effect. Therefore, the efficiency of the power transfer between the radiating and feed structure is really significant [17]. The proposed antenna design in this wok applied a rectangular aperture slot that helps to couple the electromagnetic (EM) from the field of the radiating element and leads to the optimum antenna performance.

The proposed antenna has successfully achieved a considerable performance at particular resonance frequency of $2.39 \mathrm{GHz}$ over 2.37 to $2.41 \mathrm{GHz}$ impedance bandwidth under the tolerable reflection coefficient of $S_{11}<-10 \mathrm{~dB}$. With numerous advantages, the proposed antenna is suitable for World Interoperability for Microwave Access (WiMAX) application regulated by Malaysian and Multimedia Commission (MCMC) [5]. As depicted in Figure 1, the proposed antenna operates in the range of Packet One telecommunications provider, $2.36 \mathrm{GHz}$ to $2.39 \mathrm{GHz}$, for the use in Peninsular Malaysia.

The remainder of this paper is organized as follows. In Section 2, the antenna radiating element and the aperture coupled feed technique are explained. Besides that, the integration of the three RF PIN diode switches at the three spiral arm feeds is investigated. The antenna measurement and simulation comparison of the reconfigurable radiation pattern, reflection coefficient, and gain are presented in Section 3. Finally, conclusions are drawn in Section 4.

\section{Antenna Design and RF PIN Diode Configuration}

Figure 2 depicts the configuration of the proposed antenna design. This simulated design has been performed by Computer Simulation Technology (CST) software, as CST is competence 3D electromagnetic simulation software [18]. The proposed antenna is developed from an aperture coupled feeding technique. Technically, this technique is denoted as a multilayer method which separates the radiating element and the feeding network as shown in Figures 2(a) and 2(b). Thus, a spurious effect is minimized which eventually increasing the antenna efficiency. Figure 2(a) illustrates a simulated geometry of the three radiating elements on the upper substrate. All the rectangular radiatings have similar dimensions of $38 \mathrm{~mm}$ by $16 \mathrm{~mm}$. It is discovered in simulation, in order to achieve a reconfigurable beam capability, that the radiating elements should be positioned in a sequent spiral manner of $90^{\circ}, 180^{\circ}$, and $270^{\circ}$. Meanwhile, the lower substrate deployed on both sides consists of aperture slots and spiral feed line as indicated in Figures 2(b) and 2(c), respectively.

Working principle of the proposed antenna aperture coupled feeding shows that the optimum dimension and position of aperture slot is ultimately crucial. This determines the amount of power transferred from the antenna spiral feed line to the radiating element. Hence, the reflected power at the source is minimized. Therefore, the performances of the proposed antenna such as gain, efficiency, and radiation pattern are preserved to be optimal. Presented antenna implemented a rectangular aperture slot with dimension of $14.4 \mathrm{~mm}$ by $1.25 \mathrm{~mm}$ placed at $10 \mathrm{~mm}$ away from the edge of the rectangular radiating arm. The slots dimension can be obtained by resolving the following $[1,17]$ :

$$
\begin{gathered}
L_{s}=0.01 \lambda_{o}, \\
W_{s}=0.115 \lambda_{o}, \\
\lambda_{o}=\frac{c}{f} .
\end{gathered}
$$

As shown in Figure 2(c), the switchable antenna is achieved by integrating the RF switches to the antenna spiral feed arm (S-Arm) instead of the radiating element. This helps to minimize power deteriorations by the introduction of the surface mount component (SMC) [10, 11, 14-16]. Switches A, $\mathrm{B}$, and $\mathrm{C}$ are placed at the optimum location of S-Arm 1, 


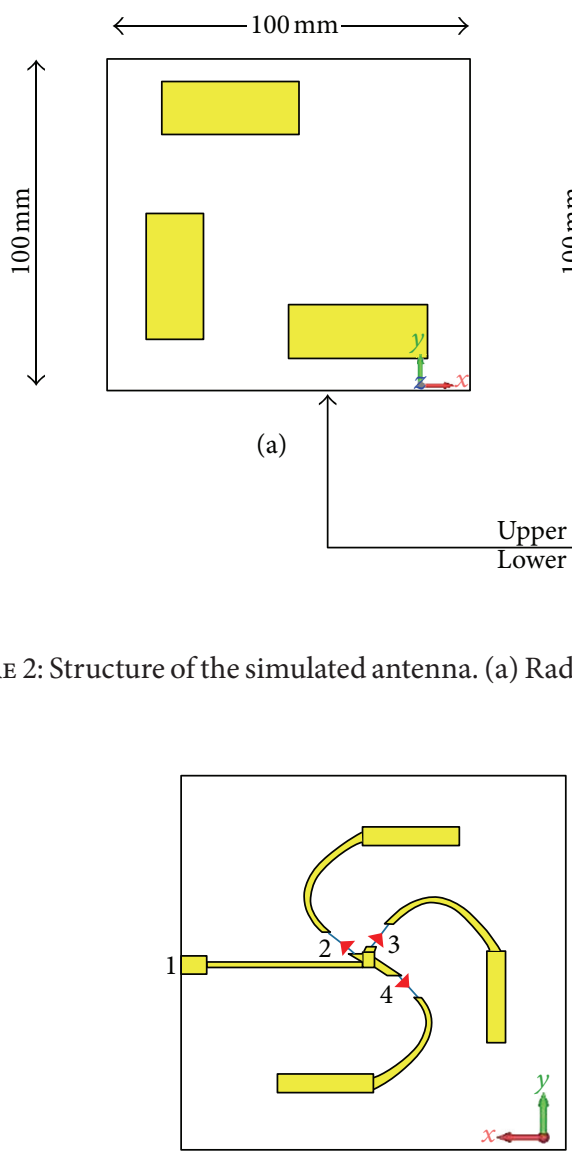

(a)

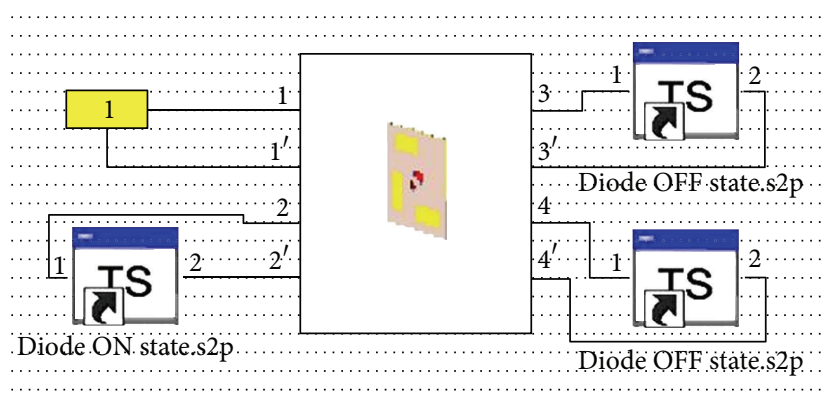

(b)

FIGURE 3: Schematic diagram of the TSB implementation to the antenna. (a) Port creation of the antenna design. (b) TSB attached to the antenna.

S-Arm 2, and S-Arm 3, respectively. The R-RF switches configuration of $\mathrm{ON}$ state indicates that more RF current will surge to the radiating element. In contrast, the OFF state condition causes gap between the middle line and the respective S-Arm which lead to no current flow through the gap. Such circuit configuration can be considered as circuit maker or a circuit breaker. This concept is proven through simulation by representing R-RF switches with a copper strip line or a touchstone (TS) block. The presence of the copper strip shows that R-RF switches in ON state and vice versa.

TS denoted as SnP file is an ASCII text file used for documenting the $n$-port network parameter data of an active device or passive interconnect network. This SnP file of the deployed BAR50-02V PIN diode is obtained from the manufacturer's website [19]. Based on the simulation result, the antenna performance can be predicted before the optimized antenna design is fabricated with the surface mount component (SMC).

Figures 3(a) and 3(b) show the schematic diagram of the TS implementation to the antenna. Firstly, the discrete port is drawn from the source edge to the passive edge where all antenna's R-RF switches are positioned. TS consists of two blocks: (1) diode ON state and (2) diode OFF state. In CST schematic, the TS is imported and positioned to the

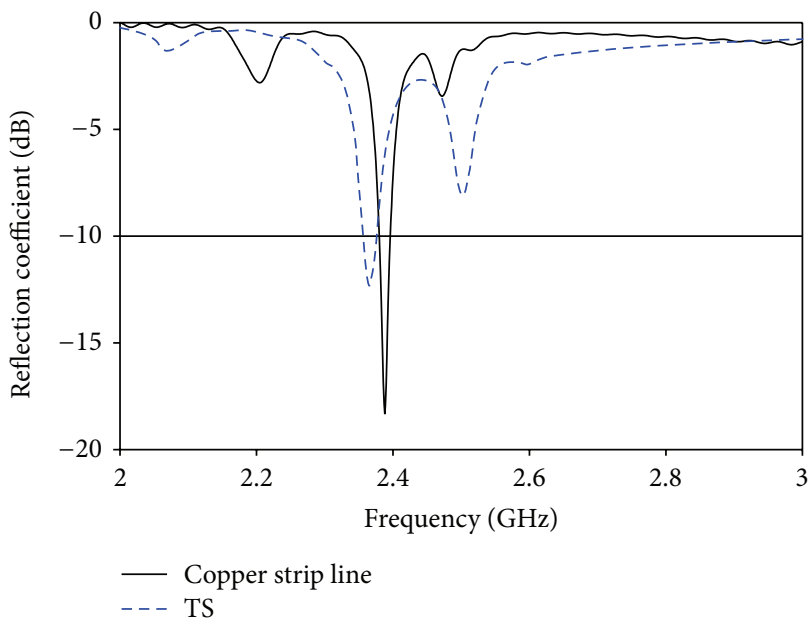

FIGURE 4: Comparison of the simulated reflection coefficient result.

desired predefined reconfigurable state. Such configuration is depicted in Figure 3 where the source port defined as port 1, switch A as port 2 (diode ON state), switch B as port 3 (diode ON state), and switch $\mathrm{C}$ as port 4 (diode ON state). Figure 4 illustrates the comparison of the $S_{11}$ result of 


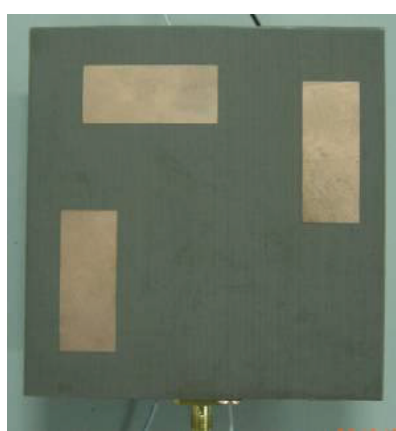

(a)

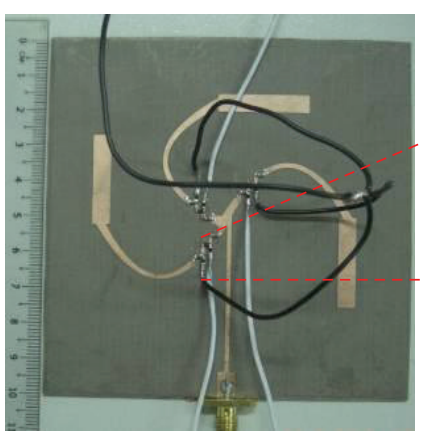

(b)

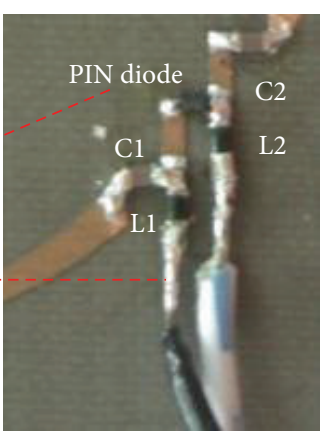

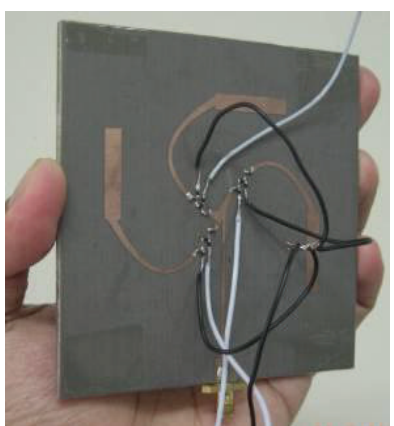

(c)

FIGURE 5: Geometry of the fabricatedantenna structure. (a) Radiating element surface. (b) Spiral feed network integrates with RF switches. (c) Antenna layout.

TABLE 1: PIN diode switches configuration of the measured and simulated antenna.

\begin{tabular}{|c|c|c|c|c|}
\hline \multirow{3}{*}{$\begin{array}{l}\text { Type of switch } \\
\text { Reconfigurable RF } \\
\text { switches (R-RFS) }\end{array}$} & \multirow{2}{*}{$\begin{array}{c}\begin{array}{c}\text { Number of PIN } \\
\text { diode switch }\end{array} \\
\text { A }\end{array}$} & \multicolumn{3}{|c|}{ PIN diode status } \\
\hline & & OFF & ON & ON \\
\hline & B & $\mathrm{ON}$ & $\mathrm{ON}$ & OFF \\
\hline & $\mathrm{C}$ & $\mathrm{ON}$ & ON & $\mathrm{ON}$ \\
\hline \multicolumn{2}{|c|}{ Simulated peak beam angle } & $340^{\circ}$ & $30^{\circ}$ & $50^{\circ}$ and $325^{\circ}$ \\
\hline \multicolumn{2}{|c|}{ Measured peak beam angle } & $320^{\circ}$ & $35^{\circ}$ & $43^{\circ}$ and $330^{\circ}$ \\
\hline \multicolumn{2}{|c|}{ Simulated total antenna efficiency } & $83.68 \%$ & $83.74 \%$ & $85.97 \%$ \\
\hline \multicolumn{2}{|c|}{ Measured total antenna efficiency } & $75.8 \%$ & $76.4 \%$ & $78.2 \%$ \\
\hline \multicolumn{2}{|c|}{ Simulated gain $(\mathrm{dBi})$} & 6.281 & 5.542 & 5.154 \\
\hline \multicolumn{2}{|c|}{ Measured gain $(\mathrm{dBi})$} & 3.35 & 3.21 & 2.80 \\
\hline \multicolumn{2}{|c|}{ Simulated HPBW (degree) } & $69^{\circ}$ & $122.9^{\circ}$ & $70.3^{\circ}$ \\
\hline \multicolumn{2}{|c|}{ Type of radiation pattern } & \multicolumn{2}{|c|}{ Directional beam } & Divisive broadside \\
\hline
\end{tabular}

the antenna with TS and antenna with copper strip line. From Figure 4, the TS reflection coefficient result has shifted to the left approximately $10 \mathrm{MHz}$ with reflection to the copper strip line resonant frequency of $2.39 \mathrm{GHz}$. Besides, the second harmonic of TS technique is bigger compared to the copper strip line. Moreover, the impedance matching for TS is better compared to the copper strip line. Overall, the performance of both techniques is slightly different due to some power excited has been absorbed by the PIN diode.

Figure 5 shows the fabricated antenna with integration of RF switching circuit into its spiral feeding network. The $\mathrm{R}-\mathrm{RF}$ switches circuit is developed from the surface mount component (SMC). It consists of one PIN diode, two DC (direct current) block capacitors, two RF choke inductors, and a DC supply. The DC source is inserted to the inductor that performed as a short circuit. However, the capacitor only allows the alternating current $(\mathrm{AC})$ to pass through instead of choke the DC. Therefore, the DC flows in the other direction and ON the PIN diode. The DC supply of 5 volts is induced through the white wire and shorted to the ground via the black wire. The predefined reconfigurable direction to a desired application can be controlled via the "ON" and "OFF" switches as tabulated in Table 1.
Throughout the research, all measurement processes were carried out in the Antenna and Microwave Lab (AMRELLAB) of Universiti Malaysia Perlis (UniMAP) with the help of Agilent Technologies E5071C (9 kHz to $8.5 \mathrm{GHz})$ Network Analyzer, and 3D/2D Atenlab Anechoic Chamber. As depicted in Figure 6, the antenna under test (AUT) performs as a transmitter, and a double ridged horn antenna functions as a receiver. The line of sight (LOS) between the antenna and the receiver is kept at $30 \mathrm{~m}$.

\section{Results and Discussion}

The measurements show that the proposed antenna has successfully achieved a minimum reflection coefficient of less than $-10 \mathrm{~dB}\left(S_{11}<-10 \mathrm{~dB}\right)$. With certain R-RFS configuration, the return loss of $2.39 \mathrm{GHz}$ is stated at $-18.4 \mathrm{~dB},-18.3 \mathrm{~dB}$, and $-27 \mathrm{~dB}$ as shown in Figures $7(\mathrm{a}), 7(\mathrm{~b})$, and $7(\mathrm{c})$, respectively. Those figures indicate that the $90 \%$ power that has been transmitted is contributed by proper alignment between the proposed antenna spiral feed line (bottom substrate) and its radiating elements (top substrate).

A sufficient interelement spacing (IES) of the proposed antenna for three R-RFS arrangements is proven through 


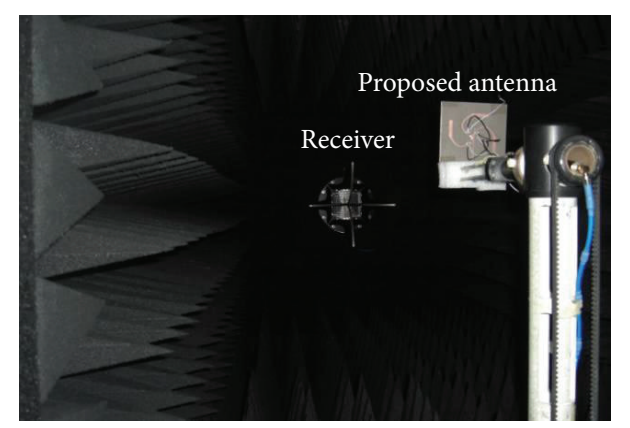

(a)

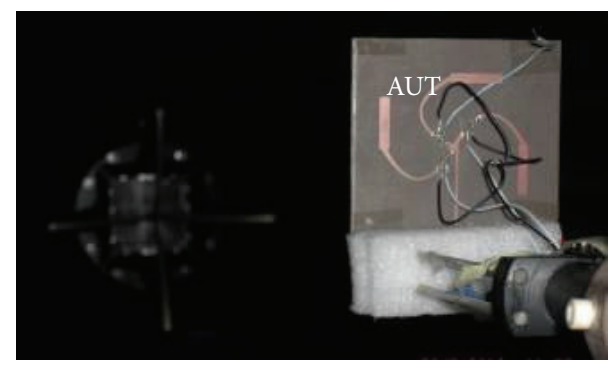

(b)

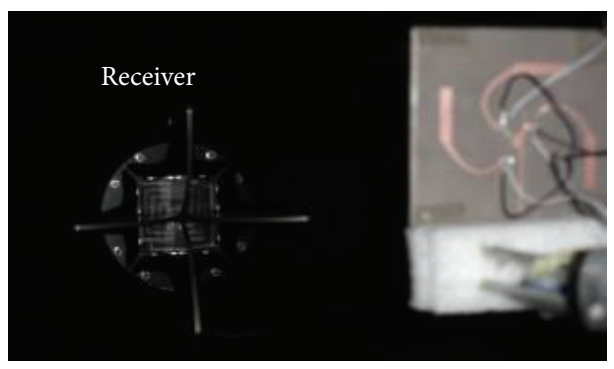

(c)

FIgure 6: Positions of the proposed antenna in the anechoic chamber. (a) Point-to-point positioned. (b) The proposed antenna. (c) Receiver (double ridged horn) antenna.

the surface current distribution. In Figure 8(a), it is observed that more inset current has flown to the radiating elements number two and three when R-RFS B and C are ON. Less current has been attracted to the adjacent radiating element number one. Figure 8(b) depicts that all radiating elements functioned properly after receiving a number of excited currents from the SMA port. Radiating element number two has approximately null current distribution as shown in Figure $8(\mathrm{c})$. This leads to more current surge in the elements number one and three. Generally, the presented antenna has good antenna isolation and eventually enhanced the radiation efficiency and antenna efficiency to more than $85 \%$ and $83 \%$, respectively.

Figures 9 and 10 depict the simulated 3D and measured radiation pattern of the PIN diode switches configuration. It is realized in both figures that the pattern is radiated on the $z-y$ axis at the resonant frequency of $2.39 \mathrm{GHz}$ for WiMAX application. The proposed antenna achieved the reconfigurable pattern by controlling the R-RFS switches with the implementation of the spiral feed arm design. Spiralling feed with the rectangular radiating element at the position of $0^{\circ}, 90^{\circ}$ and $180^{\circ}$ contributed to the phase shift of the EM wave. Moreover, the main lobe radiation can be tuned to the desired direction with certain R-RFS configuration as summarized in Table 1 . The high gain measurements and simulations of the proposed antenna can be attributed to the good coupling from the feed line to the radiating surface through the appropriate size, position, and shape of aperture slots. The measurements show a very good agreement with simulations where the radiation patterns are formed successful with respect to the directional and divisive broadside beam characteristics.
Figures 10(a) and 10(b) show the measured polar directional radiation pattern with the normalized value. As R-RFS $\mathrm{B}$ and $\mathrm{C}$ are $\mathrm{ON}$, the antenna radiation pattern is directed to $320^{\circ}$ with a gain of $3.35 \mathrm{dBi}$ and HPBW of $69^{\circ}$ as revealed in Figure 10(a). Figure 10(b) depicts the antenna beam pointed to $35^{\circ}$ with a gain of $3.21 \mathrm{dBi}$ and HPBW of $122.9^{\circ}$ when all R-RFSs are ON. Figure 10(c) demonstrates the divisive broadside radiation pattern headed to $43^{\circ}$ and $330^{\circ}$ with a gain of $2.80 \mathrm{dBi}$ and HPBW of $70.3^{\circ}$ by turning ON the R-RFS $\mathrm{A}$ and $\mathrm{C}$. It is realized that the directional beam has a better peak gain of $3.35 \mathrm{dBi}$ and $3.21 \mathrm{dBi}$ compared to the broadside beam with maximum gain of $2.80 \mathrm{dBi}$. Based on the result, the proposed antenna is able to cater for the existence of the WiMAX user between $90^{\circ}$ and $-90^{\circ}$ by directing the beam to the wanted user direction.

\section{Conclusion}

A novel patch array antenna design with directional and divisive broadside characteristic is proposed. The antenna applied an aperture coupled feed network in order to reduce the signal deterioration due to the implementation of the RRFS. It is discovered that a spiral feed design effectively contributed to the achievement of the reconfigurable radiation pattern. Through certain R-RFS configuration of the spiral feed arm, the proposed antenna is able to direct its radiating beam to the angles of $320^{\circ}$ or $35^{\circ}$ and divisive broadside at directions of $43^{\circ}$ and $330^{\circ}$. Therefore, the proposed antenna with a wider HPBW can cover the subscriber in the range between $-90^{\circ}$ to $+90^{\circ}$. For all PIN diode arrangements, the antenna well performed at resonant frequency of $2.39 \mathrm{GHz}$ 


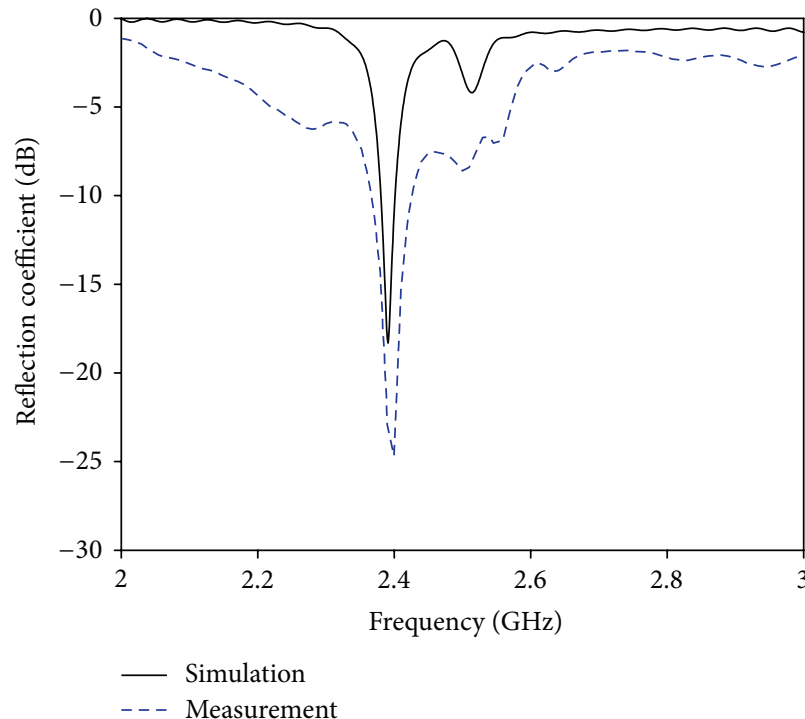

(a)

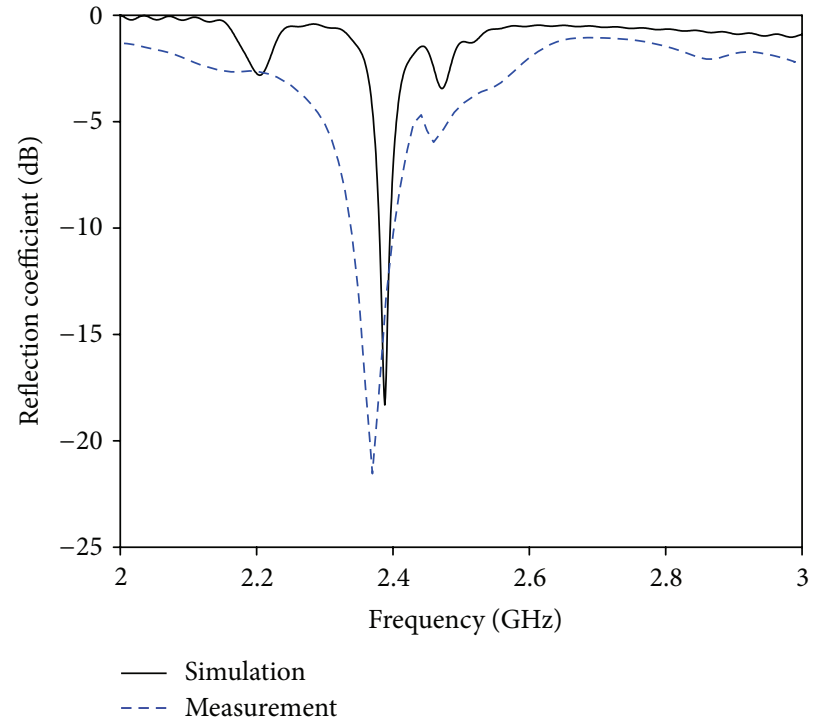

(b)

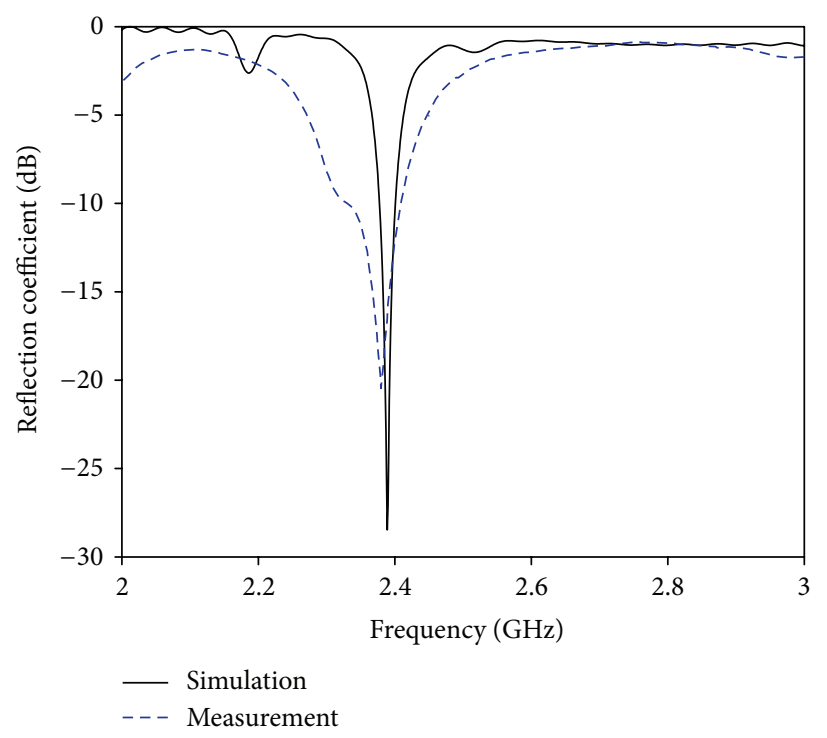

(c)

FIGURE 7: Measured and simulated reflection coefficient of the proposed antenna. (a) R-RFS B and C are ON. (b) R-RFS A, B, and C are ON. (c) R-RFS A and C are ON. The R-RFS that was not mentioned is in OFF state.

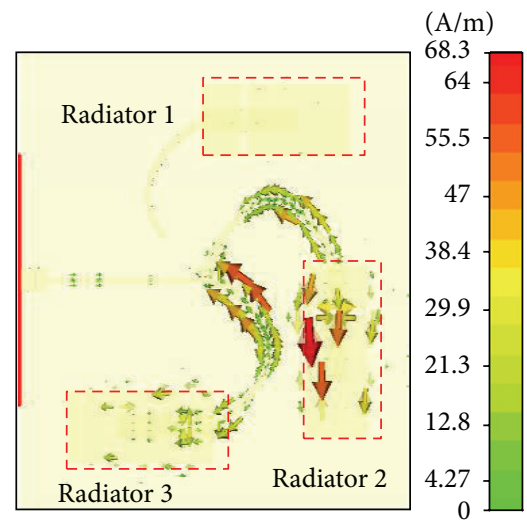

(a)

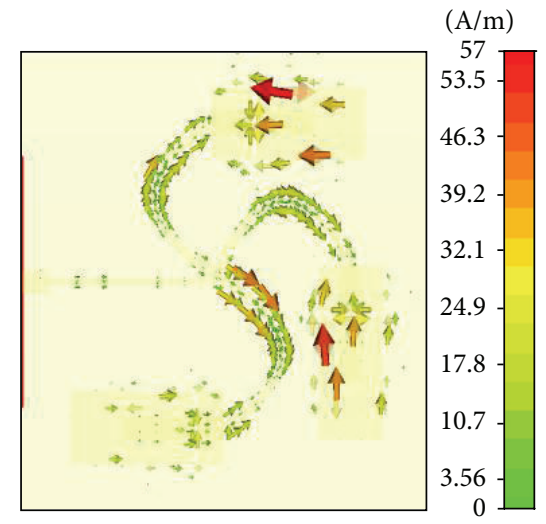

(b)

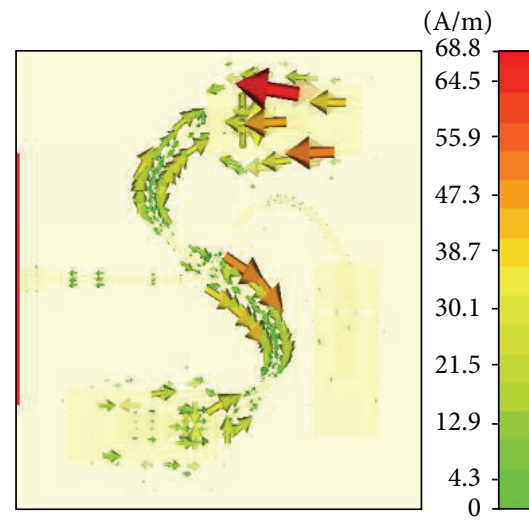

(c)

FiguRE 8: Surface current distributions of the antenna at $2.39 \mathrm{GHz}$ (a) R-RFS B, and C are ON. (b) R-RFS A, B and C are ON. (c) R-RFS A and $\mathrm{C}$ are $\mathrm{ON}$. The R-RFS that was not mentioned is in OFF state. 


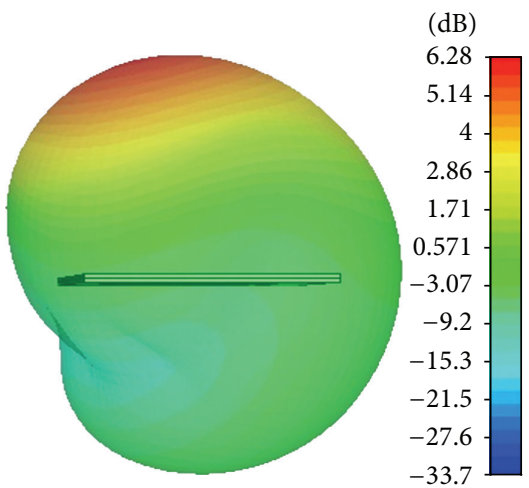

(a)

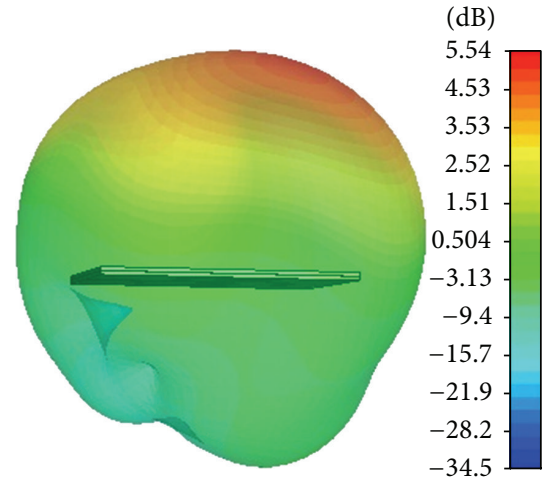

(b)

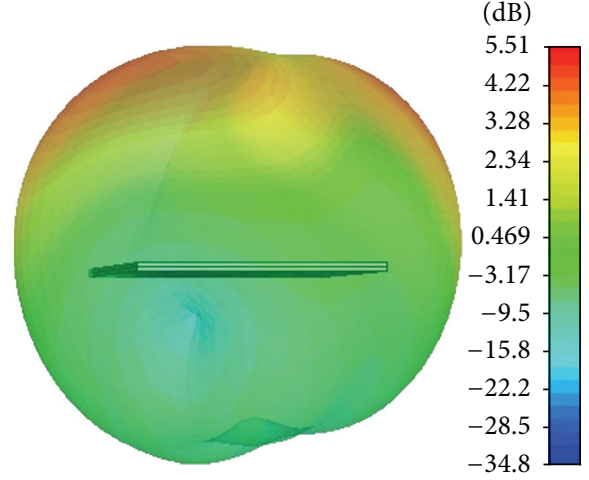

(c)

FIGURE 9: Simulated 3D radiation pattern of the proposed antenna at $2.39 \mathrm{GHz}$. (a) R-RFS B and C are ON. (b) R-RFS A, B, and C are ON. (c) R-RFS A and C are ON. The R-RFS that not was mentioned is in OFF state.

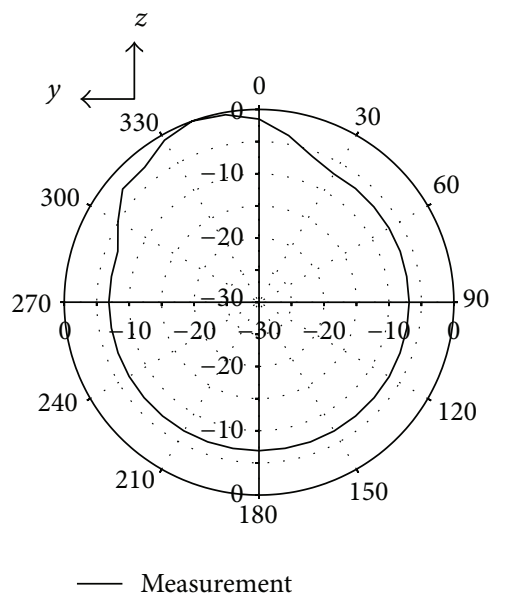

(a)

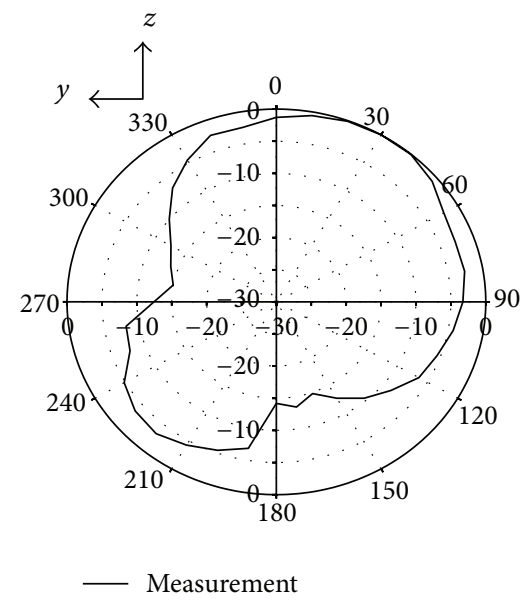

(b)

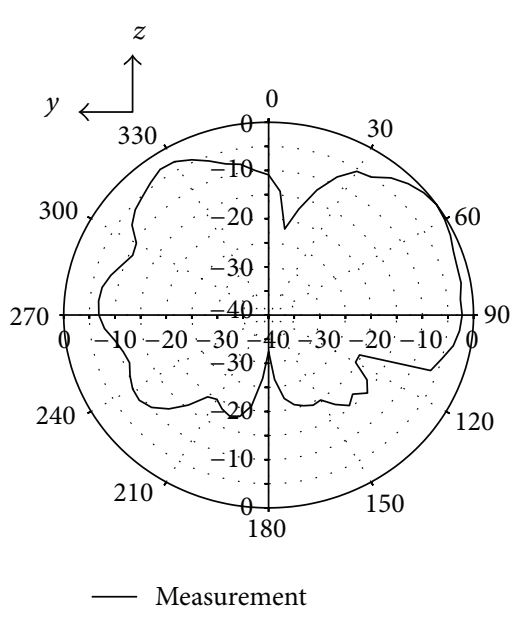

(c)

Figure 10: Measured radiation pattern of the proposed antenna at $2.39 \mathrm{GHz}$. (a) R-RFS B, and C are ON. (b) R-RFS A, B and C are ON. (c) R-RFS A and C are ON. The R-RFS that not was mentioned is in OFF state.

under tolerable $S_{11}<-10 \mathrm{~dB}$. On the other hand, the antenna has achieved a compact physical dimension of $100 \mathrm{~mm}$ by $100 \mathrm{~mm}$. Moreover, the proposed antenna radiating element occupied a simple shape design yet was able to radiate at a peak gain of $3.35 \mathrm{dBi}$. The proposed antenna with numerous compensations has further confirmed its feasibility as a portable IEEE 802.16d fixed WiMAX and IEEE 802.16e mobile WiMAX application. A future research of PIN diode circuit modelling with various inductor and capacitor values for WiMAX application will be investigated.

\section{Acknowledgments}

The authors acknowledge the contributions of Universiti Malaysia Perlis (UniMAP) and the Ministry of Malaysian Higher Education (MOHE) for the Ph.D. scholarship of Muzammil Jusoh which enabled the production of this paper. Our gratitude also goes to members of UniMAP's Advanced Communication Engineering Centre (ACE) of School Computer and Communication Engineering and Wireless Communication Centre (WCC), Universiti Teknologi Malaysia.

\section{References}

[1] C. A. Balanis, Antenna Theory Analysis and Design, John Wiley \& Sons, 1997

[2] M. T. Ali, M. N. M. Tan, T. A. Rahman, M. R. Kamarudin, M. F. Jamlos, and R. Sauleau, "A novel of reconfigurable planar antenna array (RPAA) with beam steering control," Progress in Electromagnetics Research B, no. 20, pp. 125-146, 2010.

[3] Y. Yusuf and X. Gong, "A low-cost patch antenna phased array with analog beam steering using mutual coupling and reactive loading," IEEE Antennas and Wireless Propagation Letters, vol. 7, pp. 81-84, 2008.

[4] H. Fayad and P. Record, "Multi-feed dielectric resonator antenna with reconfigurable radiation pattern," Progress in Electromagnetics Research, vol. 76, pp. 341-356, 2007.

[5] http://www.skmm.gov.my.

[6] Y. B. Jung, A. V. Shishlov, and S. O. Park, "Cassegrain antenna with hybrid beam steering scheme for mobile satellite communications," IEEE Transactions on Antennas and Propagation, vol. 57, no. 5, pp. 1367-1372, 2009.

[7] J. Ouyang, F. Yang, S. W. Yang, Z. P. Nie, and Z. Q. Zhao, "A novel radiation pattern and frequency reconfigurable microstrip 
antenna on a thin substrate for wide-band and wide-angle scanning application," Progress in Electromagnetics Research Letters, vol. 4, pp. 167-172, 2008.

[8] G. Li, S. Yang, Y. Chen, and Z. Nie, "A novel electronic beam steering technique in time modulated antenna arrays," Progress in Electromagnetics Research, vol. 97, pp. 391-405, 2009.

[9] S. V. S. Nair and M. J. Ammann, "Reconfigurable antenna with elevation and azimuth beam switching," IEEE Antennas and Wireless Propagation Letters, vol. 9, pp. 367-370, 2010.

[10] M. Jusoh, M. F. Jamlos, M. F. Malek, M. R. Kamarudin, and M. S. Mustafa, "A switchable Ultra-wideband (UWB) to tri-band antenna design," in Proceedings of the Antennas \& Propagation Conference, Loughborough, Loughborough, UK, November 2011.

[11] M. Jusoh, M. F. Jamlos, M. R. Kamarudin et al., "A reconfigurable Ultra-wideband (UWB) compact tree-design antenna system," Journal of Progress in Electromagnetic and Research $C$, vol. 30, pp. 131-145, 2012.

[12] M. A. Saed, "Reconfigurable broadband microstrip antenna fed by a coplanar waveguide," Progress in Electromagnetics Research, vol. 55, pp. 227-239, 2005.

[13] F. Ghanem, J. R. Kelly, and P. S. Hall, "Switched UWB to narrowband planar monopole antenna," in Proceedings of the 4th European Conference on Antennas and Propagation (EuCAP '10), Barcelona, Spain, April 2010.

[14] M. F. Jamlos, O. A. Aziz, T. A. Rahman et al., "A beam steering radial line slot array (RLSA) antenna with reconfigurable operating frequency," Journal of Electromagnetic Waves and Applications, vol. 24, no. 8-9, pp. 1079-1088, 2010.

[15] M. F. Jamlos, T. A. Rahman, M. R. Kamarudin, P. Saad, M. Amir Shamsudin, and A. M. M. Dahlan, "A novel adaptive Wi-Fi system with RFID," Progress in Electromagnetics Research, vol. 108, pp. 417-432, 2010.

[16] M. F. Jamlos, T. A. Rahman, M. R. Kamarudin, P. Saad, O. A. Aziz, and M. A. Shamsudin, "Adaptive beam steering of RLSA antenna with RFID technology," Progress in Electromagnetics Research, vol. 108, pp. 65-80, 2010.

[17] R. Garg, P. Bhartia, I. Bahl, and A. Ittipiboon, Microstrip Antenna Design Handbook, Artech House, 2001.

[18] http://www.cst.com/.

[19] http://www.infineon.com/. 

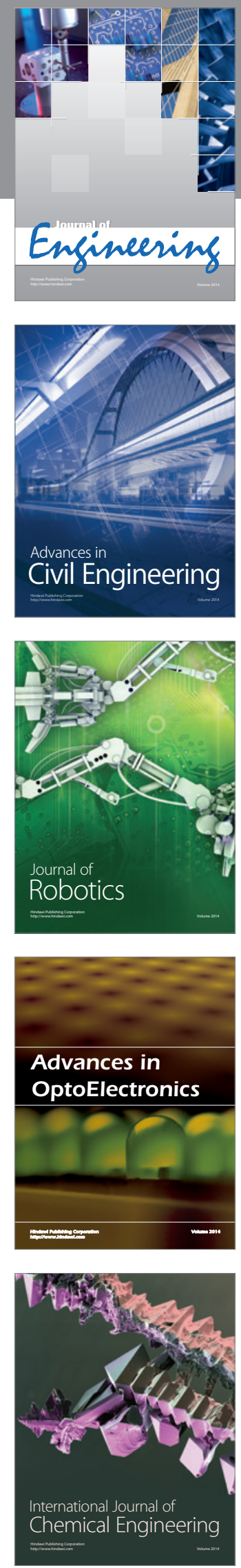

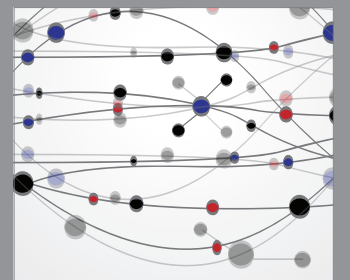

The Scientific World Journal
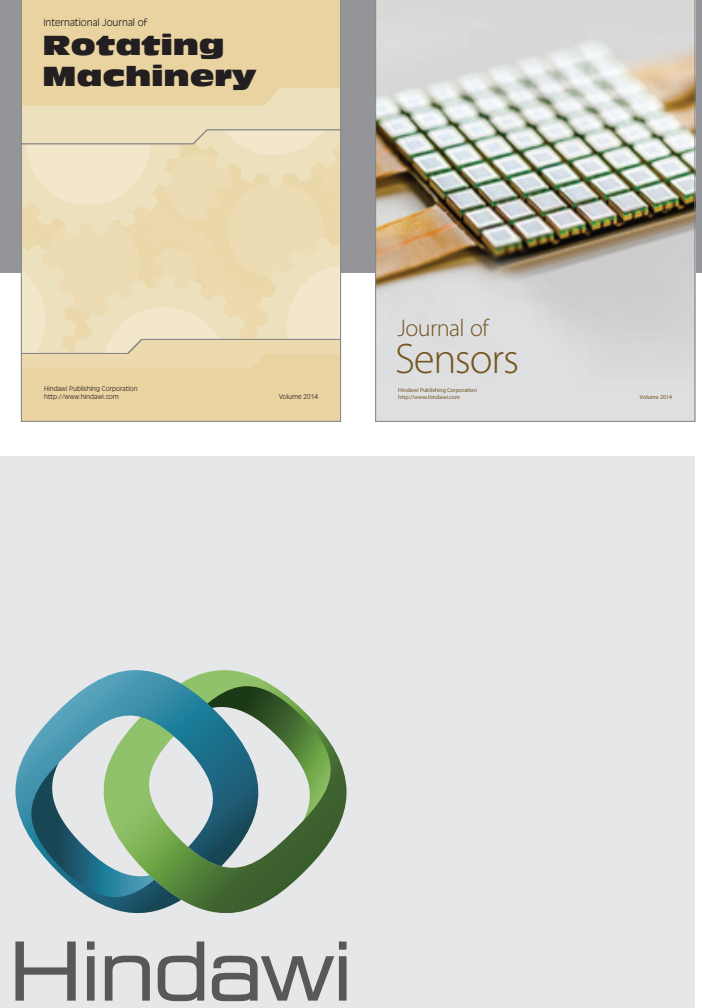

Submit your manuscripts at http://www.hindawi.com
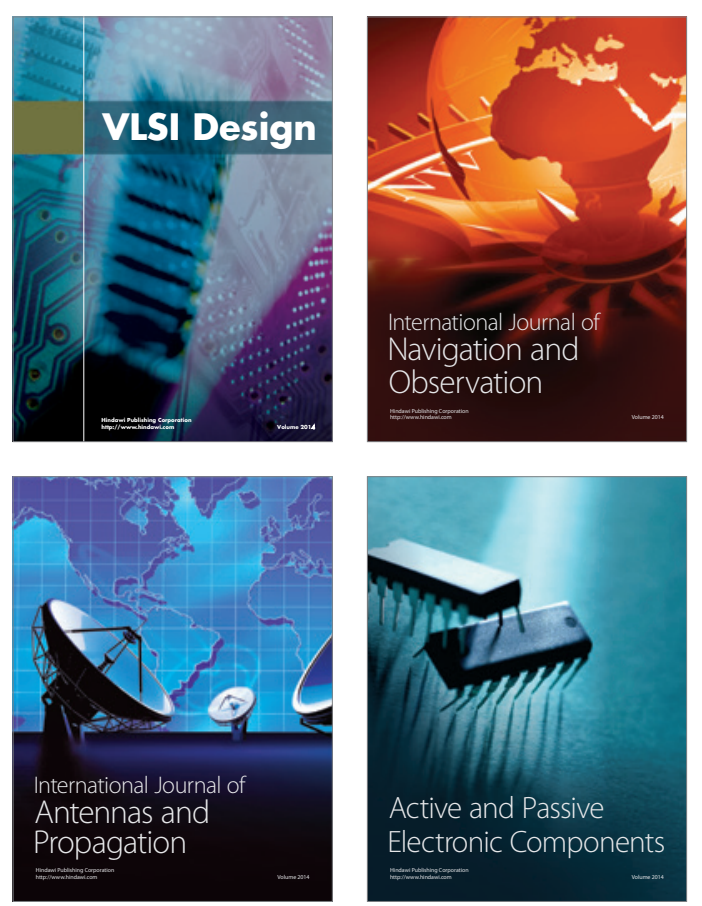
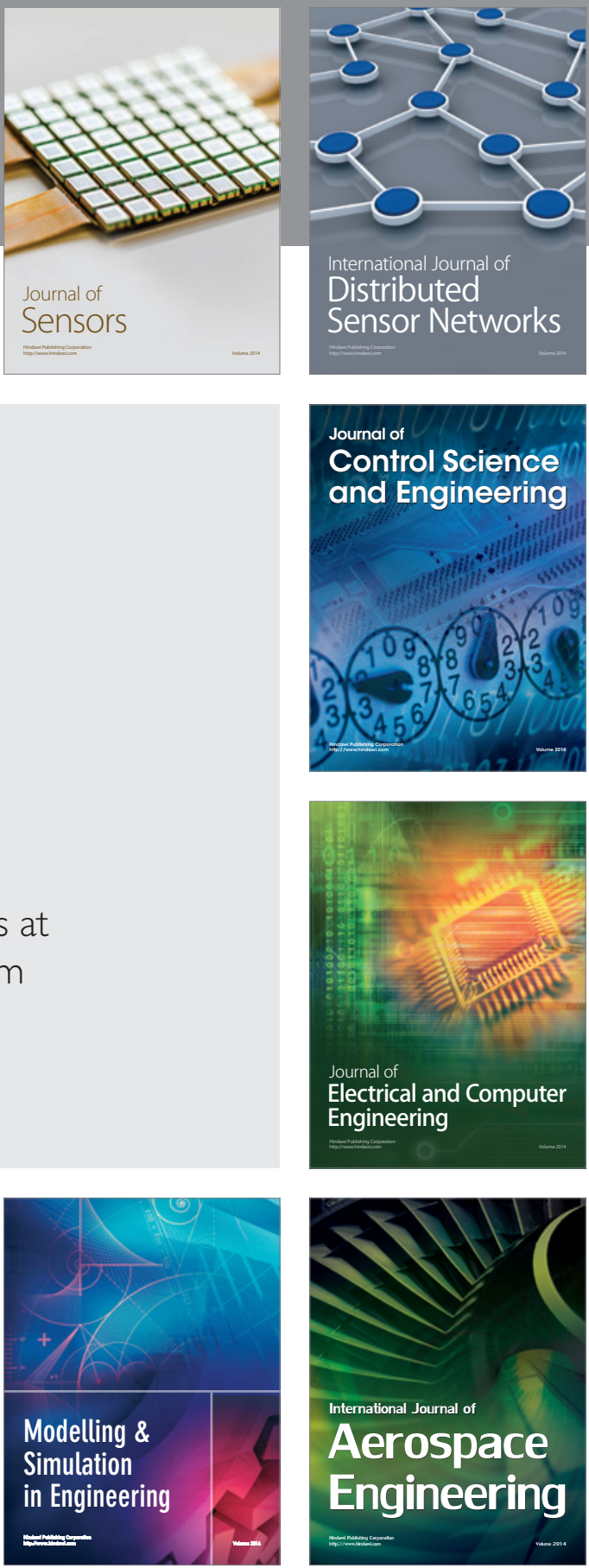

Journal of

Control Science

and Engineering
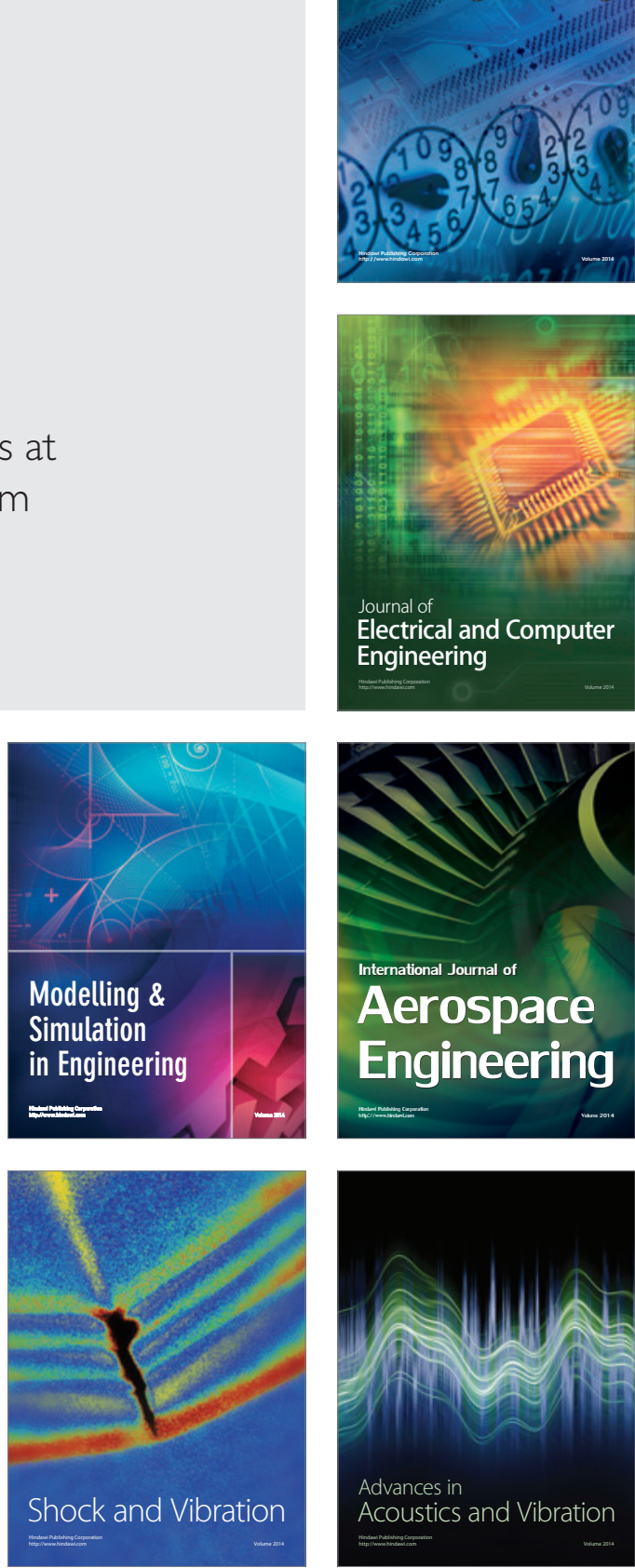